\title{
A VENTILATION SYSTEM FOR AN INTENSIVE CARE UNIT
}

\author{
E. CARDEN, M.A., M.B., B.CHm., D.A. ${ }^{\circ}$
}

The AIM of setting up the apparatus described in this paper was to provide a ventilator that could supply a patient with any desired oxygen concentration at any minute volume, and with warm humidified gases. The apparatus should be simple to understand, easy to use, and inexpensive to purchase and operate.

\section{Apparatus (FIG. 1)}

Compressed air and oxygen lines are connected to a Veriflow Oxygen Air Ratio Controller (OnC-1). $†$ This is a combination gas mixer and flow controller operating on compressed air and oxygen supplied at $50 \mathrm{psi}$ which allows a precise setting of

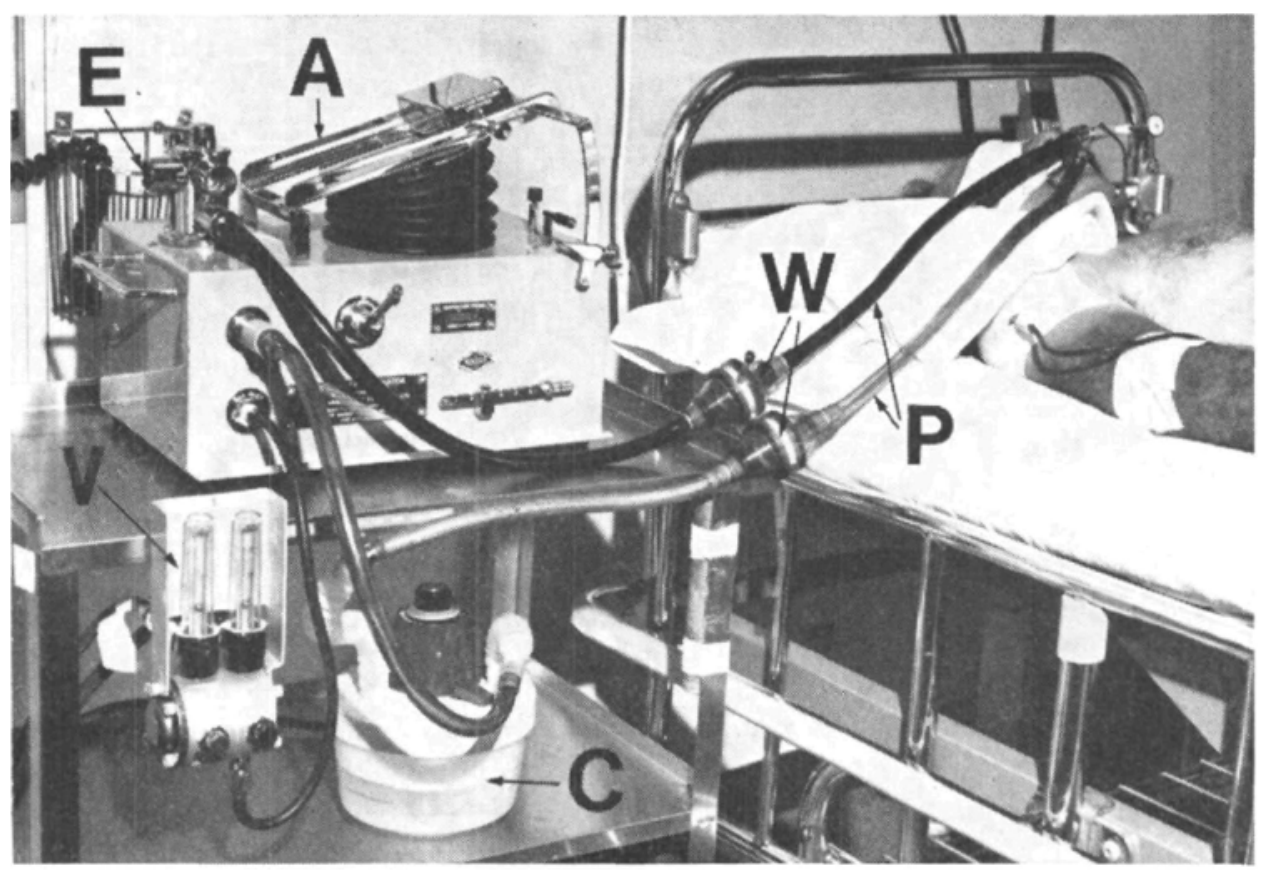

Figure 1. A ventilation system for an intensive care unit showing: the Manley ventilator (A), the Cascade humidifier (c), the Veriflow oxygen air ratio controller ( $v$ ), plastic tubing $(P)$, water traps ( $W$ ), expiratory port ( $\mathrm{E})$.

-Division of Anaesthesia, Department of Surgery, University of British Columbia, and the Intensive Care Unit, Department of Medicine, St. Paul's Hospital, Vancouver, B.C. Requests for reprints should be addressed to Dr. E. Carden, Department of Anaesthesia, Vancouver General Hospital, Vancouver, B.C.

†Veriflo Company, Medical Products Division, 250 Canal Boulevard, Richmond, California.

Can. Anaes. Soc. J., vol. 16, no. 5, September 1969 
both flow and oxygen to air ratio. The emerging gases at the desired flow rate and oxygen concentration are fed into the Manley respirator, ${ }^{10}$ having the following functional analysis:

Minute volume divider

Minute volume: 2 to $20 \mathrm{~L} / \mathrm{min}$

Frequency of ventilation: 10 to 60 per minute

Tidal volume: 200 to $900 \mathrm{ml}$

Inflation pressure: 8 to $35 \mathrm{~cm} \mathrm{H}_{2} \mathrm{O}$

Expiration-inspiration time ratio

Resistance to expiration: less than $1 \mathrm{~cm} \mathrm{H}_{2} \mathrm{O}$ at $60 \mathrm{~L} / \mathrm{min}$ flow

Peak inspiratory flow rate: $100 \mathrm{~L} / \mathrm{min}$ at $10 \mathrm{~cm} \mathrm{H}_{2} \mathrm{O}, 140 \mathrm{~L} / \mathrm{min}$ at $20 \mathrm{~cm} \mathrm{H} \mathrm{H}_{2} \mathrm{O}$, $180 \mathrm{~L} / \mathrm{min}$ at $30 \mathrm{~cm} \mathrm{H}_{2} \mathrm{O}$

Inspiration: pressure generator

Change from inspiration to expiration: by time and volume cycled (which ever limit is reached first)

Expiration: either (a) constant pressure generator (atmospheric) or $(b)$ negative pressure generator -1 to $-6 \mathrm{~cm} \mathrm{H}_{2} \mathrm{O}$

Change from expiration to inspiration: by time cycled

Overall effect: minute volume divider

The gases going to the patient are warmed and humidified by passing through a Bennett Cascade Humidifier $f$

Heater: 115 volts

Thermostat: variable

Water capacity: $775 \mathrm{cc}$

Volume between maximum and minimum levels: $300 \mathrm{cc}$

Efficiency: will deliver over 100 per cent relative to body temperature, if desired

The gases then travel to and from the patient via plastic (Bird) tubings incorporating water traps on the inspiratory and expiratory limbs (Fig. 1).

\section{Advantages}

The minute volume may be preset on the flowmeters and will remain constant despite changes in compliance. This is a great advantage over pressure-cycled ventilators, particularly in an intensive care unit (ICU), in that many patients have lung disease with changing compliance (e.g., intermittent bronchospasm) and they may have long periods of hyper- or hypoventilation, as the compliance and hence the minute volume changes with pressure-cycled ventilators.

The oxygen concentration that is optimum for the patient can be set as desired from 20 to 100 per cent. Many ventilators currently used have only two available oxygen concentrations: 100 per cent (which of course predisposes to the hazard of oxygen toxicity ${ }^{2}$ ), and an air/oxygen mixture of some fixed amount. Methods to vary the oxygen concentrations from these fixed oxygen concentrations are available, but they usually are inaccurate and necessitate the constant use of oxygen analysers.

The gases inhaled by the patient are warmed and humidified. A cold gas ultrasonic nebulizer could be used to replace the Cascade unit, if desired.

The whole apparatus is simple and easy for the ICU nursing staff to understand and use. It is robust and requires very little servicing. The cost of other ventilators

-Winley-Morris Company Ltd., 2795 Bates Road, Montreal 26, P.Q.

$\nmid$ Bennett Respiration Products Ltd., 1639 Eleventh Street, Santa Monica, California 90406. 
which will deliver a constant minute volume at any desired oxygen concentration is much greater. At the time of writing, the costs for this unit are:

$\begin{array}{lr}\text { Veriflow Oxygen Air Ratio Controller } & \$ 165.00 \\ \text { Manley Ventilator with Negative Phase Model MN-2 } & 732.00 \\ \text { Bennett Cascade Humidifier Model } 1750 & 156.75 \\ \text { Tubing and water traps } & 35.00 \\ \text { Total cost } & \$ 1088.75\end{array}$

Comparison prices of other ventilators

$\begin{array}{ll}\text { Blease Pulmoflator } & \$ 2646.00 \text { to } \$ 5046.00 \\ \text { Cape Waine Ventilator } & \$ 4265.00 \text { to } \$ 6726.00 \\ \text { Engstrom Ventilator } & \$ 5000.00 \\ \text { Emerson } & \$ 1700.00\end{array}$

\section{THE UNIT IN UsE}

The system has been used on ten patients to date. One patient had a flail chest and the remainder were suffering from pneumonia complicated by respiratory insufficiency. These latter patients were initially ventilated with a pressurecycled ventilator (Bird Mark 7,8,10, or 17) and were placed on the unit described here for the following reasons.

Bronchospasm and even changes in position stimulated coughing and resulting changes in compliance. This caused alterations in minute volume and oxygen tension as determined by blood gas estimations. Shunting may also have occurred. These changes necessitated accurate adjustment and the ability to control rapidly the oxygen concentration.

Changing over to this unit, in all cases, enabled the minute volume and hence the $\mathrm{PCO}_{2}$ to be kept at a constant level, and the arterial $\mathrm{Po}_{2}$ to be kept within physiological limits by small changes in the inspired oxygen levels. No specific problems were encountered. The unit performed reliably whenever it was used. However, the nursing staff had to be re-educated to watch the patient's chest to ensure that the patient was being ventilated, rather than to listen to a change in the sound of the ventilator. This ventilator is quiet, and a kink in the endotracheal tube or tracheostomy gives little audible warning that all is not well. (If the Manley ventilator becomes disconnected from the patient, for example, it will continue to cycle as if nothing had happened, except for the fact that the inspiratory time shortens, and a quiet swooshing sound is heard from the patient connector as the oxygen-air mixture escapes to the fresh air. In the same situation with a pressure-cycled ventilator, sound is heard from the patient connector which will continue until the patient is reconnected.) A Wright respirometer can be connected to the expiratory port to confirm the degree of ventilation.

The unit was usually used on pulmonary problems which were not easily controllable with the pressure-cycled ventilators available at the time. That an improvement in ventilation was obtained is confirmed by the consistency and normality of $\mathrm{Po}_{2}$ and $\mathrm{Pco}_{2}$ levels. 


\section{Conclusion}

This unit constitutes an efficient cheap and simple ventilation system which is ideally suited to intensive care units.

\section{SUMMARY}

A new ventilation system designed for the intensive care unit, has been tested. It functions well and is simple for the nurses to understand and operate. Inspired oxygen concentrations and minute volume adjustments are simple to adjust and maintain. The price is exceptionally competitive with other ventilation systems in current use.

\section{RÉSUMÉ}

Nous avons essayé un nouveau système de ventilation fabriqué pour une "unité de soins intensifs." Il donne un bon rendement et, pour les infirmières, il est facile à comprendre, et à manipuler. Il est facile de mettre à point et de maintenir les pourcentages d'oxygène dans l'air inspiré ainsi que le volume minute. Le prix est concurrentiel avec les autres systèmes de ventilation en usage actuellement.

\section{ACKNOWLEDGMENTS}

I would like to thank Mrs. Campbell and the staff of the intensive care unit at St. Paul's Hospital, Vancouver, for their help in the assessment of this apparatus.

\section{REFERENCES}

1. Mantey, R. W. A New Mechanical Ventilator. Anaesthesia. 16: 317 (1961).

2. Bendixen, H. H.; Egbert, L. D.; Hedley-Whyte, J.; Laver, M. B.; \& Pontoppidan, H. Respiratory Care. St. Louis: C. V. Mosby (1965). 